\title{
A high throughput method for total alcohol determination in fermentation broths
}

\author{
Peng Zhang ${ }^{1 *} \mathbb{D}$, Hao Hai ${ }^{1}$, Dongxu Sun ${ }^{1}$, Weihua Yuan², Weijie Liu', Ruru Ding ${ }^{1}$, Mengting Teng ${ }^{1}$, Lin Ma', \\ Jun $\operatorname{Tian}^{1 *}$ and Caifa Chen ${ }^{2^{*}}$
}

\begin{abstract}
Background: The potassium dichromate oxidation method used in determination of alcohols in fermentation has two major disadvantages. This method cannot be used to determine alcohols in raw fermentation broth samples, which often contain various reducing sugars. The method is not environment friendly due to the carcinogenicity of $\mathrm{Cr}(\mathrm{VI})$ used.

Results: A new method for determination of reducing sugars and total alcohols in raw fermentation broths was developed. The fermentation broth was pretreated to remove proteins, polysaccharides, glycerol and organic acids. The colorimetric change from both total alcohols and reducing sugars by potassium permanganate oxidation was measured. The portion of colorimetric change from oxidation of reducing sugars was determined by DNS test and subtracted. The remaining portion of colorimetric change was then used to calculate the total alcohol concentration in the sample.
\end{abstract}

Conclusions: Using this method, total alcohol concentration can be easily and accurately determined in both distilled samples and raw fermentation broth samples. It is fast and environmental friendly.

\section{Background}

Total alcohols and reducing sugar concentrations are two important parameters in fermentation of wine, beer and fuel ethanol [1-3]. It provides information on optimization and regulation of the fermentation process to increase the yield and quality of the products.

Several methods have been used in determination of ethanol concentration, including gas chromatographic methods [4-6], gas chromatography-mass spectrometry [7], gas chromatography combustion isotope ratio mass spectrometry [8], and liquid chromatograph-mass spectrometry $[9,10]$. The gas or liquid chromatographic methods require expensive instruments, and are time-consuming, so they cannot be widely used to closely monitor the fermentation process.

Gravimetric methods have also been used in ethanol determination (for example, the method described in the Chinese Standard GB/T 5009.48-2003). In these methods, distillation is a critical step. But as it often takes about $1 \mathrm{~h}$ to distill a sample of $100 \mathrm{ml}$, it is difficult to use these methods in high throughput tests. Ethanol

\footnotetext{
*Correspondence: zhangpeng@jsnu.edu.cn; tj-085@163.com;

chencaifa@jsnu.edu.cn

${ }^{1}$ School of Life Science, Jiangsu Normal University, Xuzhou 221116, People's Republic of China

${ }^{2}$ Key Laboratory for Biotechnology on Medicinal Plants of Jiangsu Province, Jiangsu Normal University, Xuzhou 221116, People's Republic of China
}

concentration can also be determined using ethanol oxidase or ethanol dehydrogenase, but the results are easily disturbed by the presence of various enzymes in the fermentation broth.

Chemical methods of ethanol determination are based on colorimetric changes upon reactions of chemicals such as potassium dichromate with ethanol [11, 12]. However, two problems are associated with these methods. First, the use of dichromate has been avoided by most of the world because of the carcinogenicity of $\mathrm{Cr}$ (VI). Second, the methods cannot be used to determine ethanol concentration in raw fermentation broths due to the presence of various reducing sugars and side-products, which can also react with potassium dichromate.

In the present study, we developed a new method for total alcohols and reducing sugar determination. The principle and the main procedure of this method are as the following. The fermentation broth is pretreated with $\mathrm{Ca}(\mathrm{OH})_{2}$ to remove organic acids and glycerol [13]. Organic acids and glycerol can react and precipitate with $\mathrm{Ca}(\mathrm{OH})_{2}$. Then, the fermentation broth is treated with trichloroacetic acid (TCA) to precipitate proteins and cell debris in the sample under acidic conditions [14-16]. The precipitated materials are removed by a simple centrifugation step. The supernatant is then treated with hexadecyltrimethylammoniumbromide 
(CTAB) to precipitate polysaccharides and the remaining residual proteins [17], which are removed by centrifugation. After these steps, the main interfering substance still present in the sample are reducing sugars, which are oxidized by addition of 3, 5-dinitrosalicylic acid (DNS) under alkaline conditions with heating [18], and quantitatively measured by colorimetric detection. Meanwhile, the sample is reacted with potassium permanganate (we used potassium permanganate as a replacement of potassium dichromate to avoid its carcinogenicity) in a parallel test, in which the color change from both total alcohols and reducing sugars in the sample is quantitatively measured. After subtracting the portion of absorbance increase contributed by reducing sugars, the remaining absorbance decrease can be used to calculate the total alcohol concentration in the sample.

Using this method, total alcohol concentration can be easily determined in both distilled samples and raw fermentation broth samples in a high throughput manner.

\section{Results}

Linearity and detection limits

The linearity and detection limit of glucose in reaction with DNS

Various concentrations of glucose solutions (2-fold serial dilutions from $10 \mathrm{~g} \mathrm{~L}-1$ to $0.15625 \mathrm{~g} \mathrm{~L}-1$ ) were prepared to determine the standard curve in reaction with DNS and A550 was determined. The glucose standard curve thus generated. It showed a linear range from $2.5 \mathrm{~g} \mathrm{~L}-1$ to $0.15625 \mathrm{~g} \mathrm{~L}-1$, with a regression equation of $\mathrm{y}=0.3721 \mathrm{x}+$ 0.0744 and $R^{2}=0.9988$. When the concentration of glucose exceeded $2.5 \mathrm{~g} \mathrm{~L}-1$, the A550 increase deviated from the linear standard curve (Fig. 1A).

\section{The linearity and detection limit of glucose by method of potassium permanganate oxidization}

Various concentrations of glucose (2-fold serial dilutions from $2 \mathrm{~g} \mathrm{~L}-1$ to $1.96 \mathrm{mg} \mathrm{L}-1$ ) were prepared to estabolish the standard curve of A526 increase by the potassium permanganate treatment. The standard curve displayed a
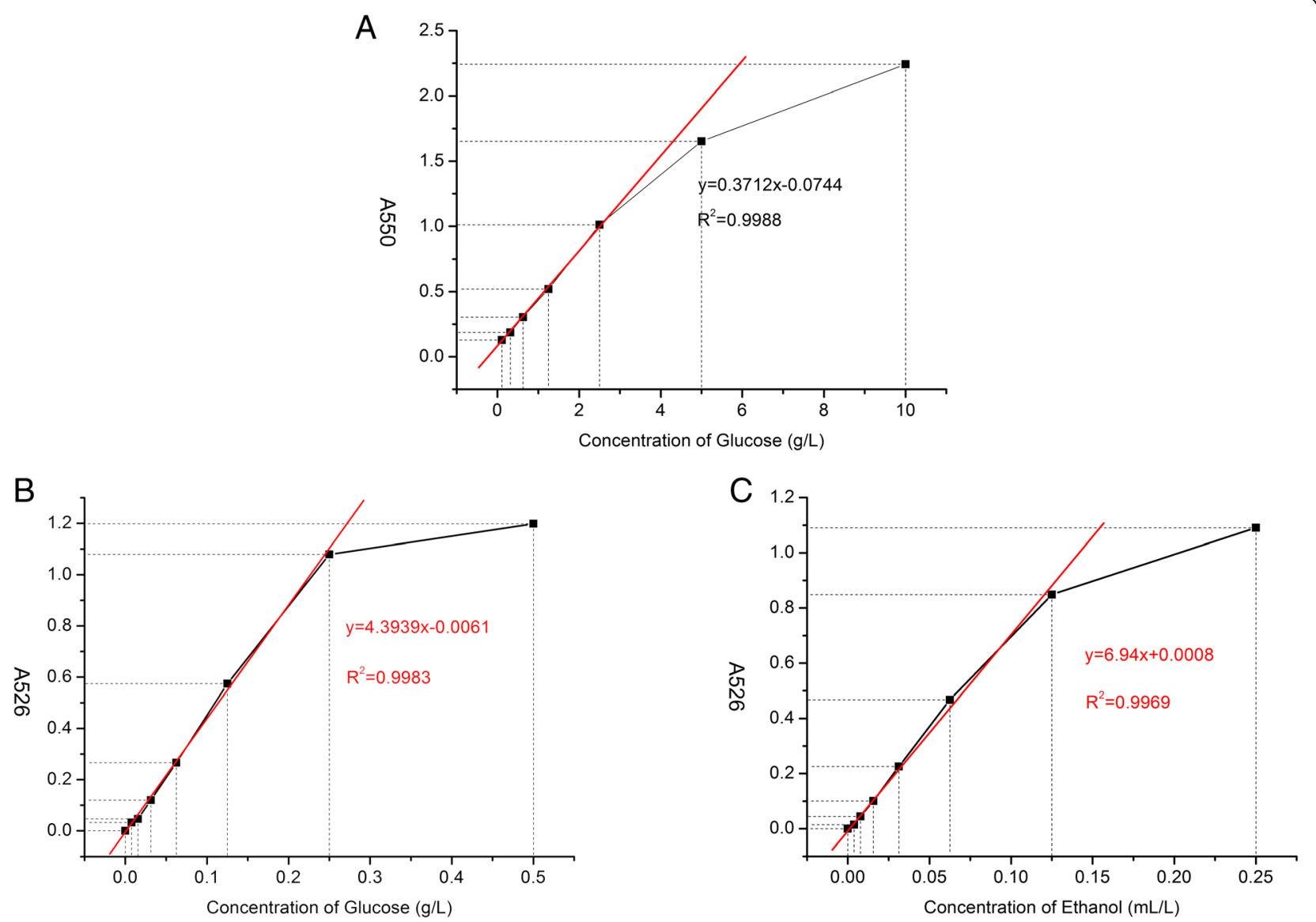

Fig. 1 Standard curves of glucose and ethanol (a DNS method for glucose; b potassium permanganate method for glucose; c: potassium permanganate method for ethanol; A526 = A526 before the reaction - A526 after the reaction) 
linear range equal and below $0.25 \mathrm{~g} \mathrm{~L}-1$, with the regression equation $y=4.3939 x-0.0061$, and $R^{2}=0.9983$. When the concentration of glucose was above $0.25 \mathrm{~g} \mathrm{~L}-1$, the A526 increase deviated from the linear standard curve (Fig. 1B).

\section{The linearity and detection limit of ethanol by method of potassium permanganate oxidization}

Various concentrations of ethanol (2-fold serial dilutions from $2 \mathrm{~mL} \mathrm{~L}-1$ to $1.96 \mu \mathrm{L} \mathrm{L}-1$ ) were prepared to estabolish the standard curve of A526 increase by the potassium permanganate treatment. A linear range was observed at ethanol concentrations equal and below $125 \mu \mathrm{L} \mathrm{L}-1$, with $y=6.94 x+0.0008$ and $R^{2}=0.9969$. However, when the concentration of ethanol exceeds $125 \mu \mathrm{LL}-1$, The A526 increase deviated from the linear standard curve (Fig. 1C).

The progression of reactions and product stability For broad application of our new method in ethanol determination, it is important that the chemical reactions proceed to the completion and the concentrations are in the linear range when the reaction is stopped, and that the products are stable. We therefore tested the product stability in our new method.

One hundred $\mu \mathrm{L}$ of 2-fold serial dilutions of glucose (from $0.25 \mathrm{~g} \mathrm{~L}-1$ to $0.0078 \mathrm{~g} \mathrm{~L}-1$ ) was mixed with $100 \mu \mathrm{L}$ of potassium permanganate, incubated at $40{ }^{\circ} \mathrm{C}$, and $\mathrm{A} 526$ was determined every $3 \mathrm{~min}$. As shown in Fig. $2 \mathrm{~A}$, the A526 increase plateaued at 80-100 min when glucose was at $0.25 \mathrm{~g} \mathrm{~L}-1$. Below $0.25 \mathrm{~g} \mathrm{~L}-1$, the A526 continued to increase beyond $120 \mathrm{~min}$ in a near linear manner.

A similar study on the reaction of ethanol with potassium permanganate indicated that the A526 reached to maximum at $30 \mathrm{~min}$, and stably maintained this level until 120 min. (Fig. 2B).
The interference of the results

Effect of various compounds on glucose determination by the DNS method

As TCA and CTAB were used in the pretreatment of fermentation broths and ethanol was produced, the effect of these compounds on glucose determination by the DNS method was measured. Four tubes of glucose solution at $4 \mathrm{mg} \mathrm{mL}-1$ were mixed with $2 \% \mathrm{TCA}, 2 \% \mathrm{CTAB}, 8 \%$ ethanol and distilled water (control) respectively, and proceeded with the DNS method. The results shown in Fig. 3A indicate that there was no significant difference between the control and the samples containing the compounds tested by statistical analysis.

\section{The effect of CTAB on ethanol determination by potassium permanganate}

Different concentrations of CTAB were added into $0.125 \mathrm{~mL} \mathrm{~L}-1$ ethanol or $0.25 \mathrm{~g} \mathrm{~L}-1$ glucose. These samples were treated as2.4. The variation of A526 was showed in Fig. 3B. CTAB cannot disturb the result when the concentration of CTAB is under $0.25 \%$.

\section{The effect of TCA on ethanol determination by potassium permanganate}

A similar test on the effect of various concentrations of TCA on ethanol determination by potassium permanganate treatment was performed. The A526 increased significantly, when the concentration of TCA exceeded 2.5\% (Fig. 3C). In this method, we pretreated our samples with $10 \%$ TCA, but when we determinate it after 10 to 100 times dilute. Therefore, the TCA concentration is below $1 \%$. So TCA and CTAB can be used in this method.

Testing the accuracy of the new method

The accuracy of detection is very important for a new method. We spiked ethanol to a pretreated sample at various
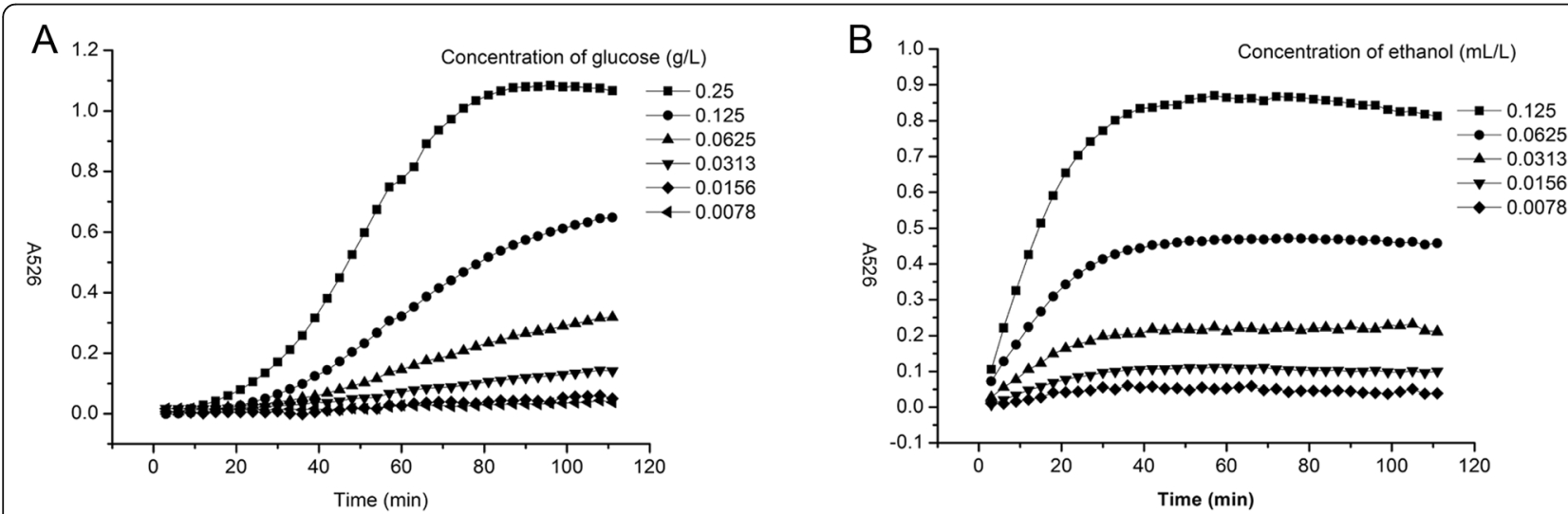

Fig. 2 The stability of oxidization (a The stability of DNS oxidization; $\mathbf{b}$ The stability of potassium permanganate oxidization; A526=A526 before the reaction - A526 after the reaction) 

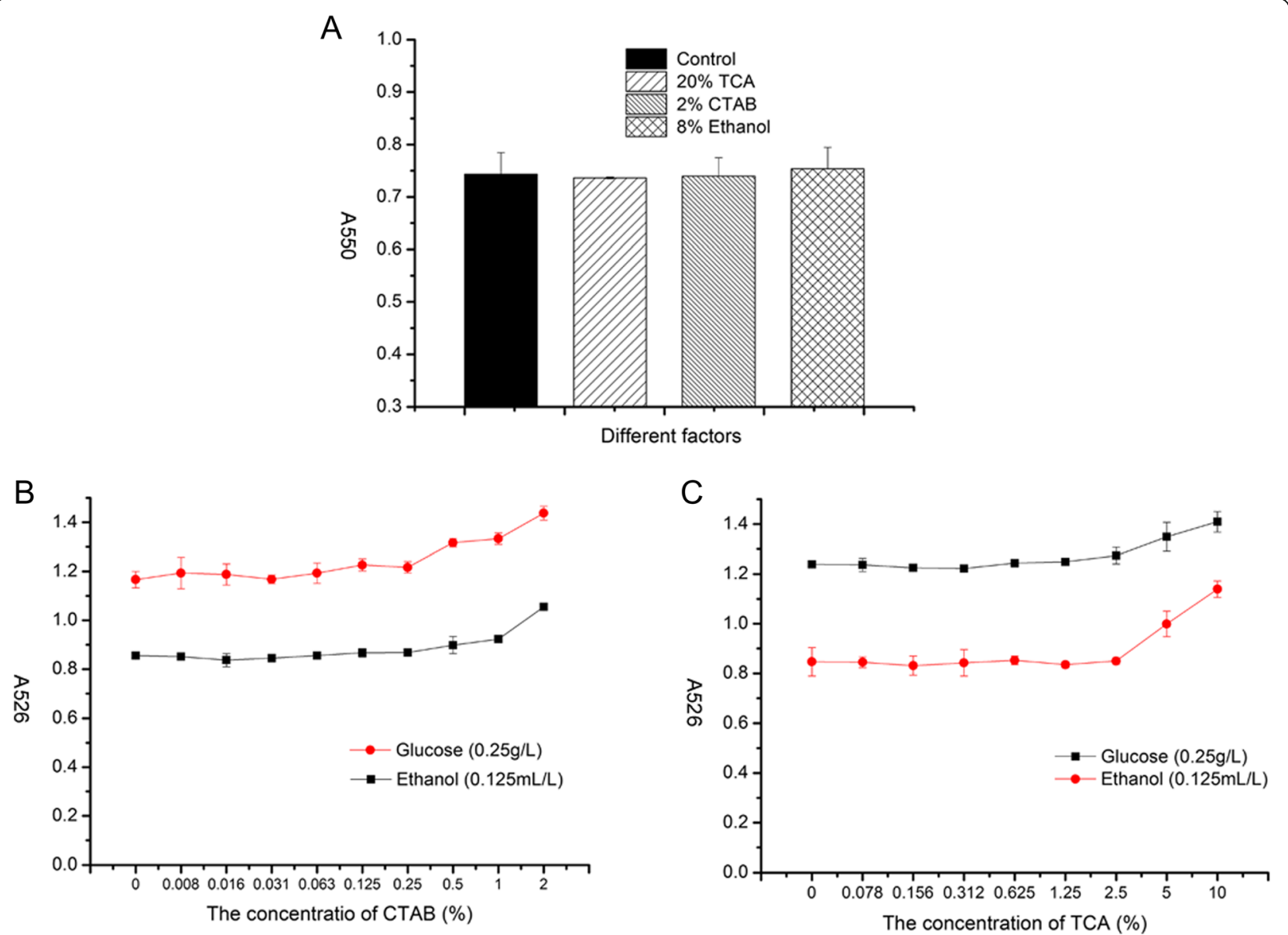

Fig. 3 The effect of different factors on the determination of glucose and ethanol (a The effect of different factors on the determination of glucose with DNS reaction; $\mathbf{b}$ The effect of CTAB in potassium permanganate reaction; $\mathbf{c}$ he effect of trichloroacetic acid in potassium permanganate reaction; $\mathrm{A} 526$ = A526 before the reaction - A526 after the reaction)

concentrations and calculated the increase in the ethanol concentration as determined by the new method. The results are showed in Table 1 . All the 10 concentrations of ethanol spiked showed high detection accuracy, with the difference between the spiked amount and the calculated increase by our new method being less than $10 \%$. Out of the 10 spiked samples, 8 showed the differences of less than $2 \%$. These results indicate that the new method is very accurate.

\section{Example for our new method}

Here we provide an example to demonstrate how to use the new method to determine ethanol concentration. Pretreated sample was prepared from an ethanol fermentation culture as described in the Materials and Methods. A small aliquot of the pretreated sample was diluted 100 -fold with water, and $0.1 \mathrm{~mL}$ of the diluted pretreated sample was mixed with $0.1 \mathrm{ml}$ of potassium permanganate solution in a 96-well plate. At the same time, the standard curves of ethanol and glucose treated with potassium permanganate were established in the same 96-well plate. The plate was kept at $40^{\circ} \mathrm{C}$ for 90 min and A526 was measured. The A526 of the diluted pretreated sample was 0.685 . Another small aliquot of the same pretreated sample was diluted 10 fold with water, and $200 \mu \mathrm{L}$ of the diluent was mixed with $600 \mu \mathrm{L}$ of DNS and kept at $100^{\circ} \mathrm{C}$ for $10 \mathrm{~min}$. After cooling down to room temperature, $200 \mu \mathrm{L}$ of the mixture was transferred to a 96-well plate and A550 was measured to be 0.2962 . Meanwhile, a standard curve of glucose was established with DNS under the same conditions. Based on the regression equation of $y=0.3712 x-0.0744$ from the glucose-DNS treatment standard curve, the concentration of reducing sugars in the diluted pretreated sample was calculated to be $0.9984 \mathrm{~g} \mathrm{~L}-1$. Because the pretreated sample was diluted 10 -fold, the reducing sugar concentration in the undiluted pretreated sample was $9.984 \mathrm{~g} \mathrm{~L}-1$. Then, we calculated how much A526 could be generated from $99.84 \mathrm{mg} \mathrm{L}-1$ of glucose that was present in the 100-fold dilution of the pretreated sample, by reacting with potassium permanganate. Based 
Table 1 Determination of accuracy of the RSSAA method

\begin{tabular}{llll}
\hline $\begin{array}{l}\text { NO. } \\
\text { spiked }\end{array}$ & $\begin{array}{l}\text { Ethanol concentration concentration } \\
\text { detected }^{\mathrm{a}}\end{array}$ & Detection accuracy \\
\hline & $(\%, \mathrm{VN})$ & $(\%, \mathrm{~V} N)$ & $(\%)$ \\
1 & 1.93 & $2.01 \pm 0.09$ & $104.1 \pm 4.7$ \\
2 & 3.79 & $3.85 \pm 0.12$ & $101.6 \pm 3.2$ \\
3 & 5.57 & $5.98 \pm 0.28$ & $107.4 \pm 5$ \\
4 & 7.3 & $7.32 \pm 0.15$ & $100.3 \pm 2.1$ \\
5 & 8.95 & $9.08 \pm 0.09$ & $101.5 \pm 1$ \\
6 & 10.55 & $10.61 \pm 0.11$ & $100.6 \pm 1$ \\
7 & 12.11 & $12 \pm 0.12$ & $99.1 \pm 1$ \\
8 & 13.59 & $13.72 \pm 0.25$ & $101 \pm 1.8$ \\
9 & 15.02 & $15.12 \pm 0.21$ & $100.7 \pm 1.4$ \\
10 & 16.42 & $16.44 \pm 0.02$ & $100.1 \pm 0.1$ \\
\hline
\end{tabular}

${ }^{\mathrm{a}}$ The values $=$ measured values $-1.5 \%$ (ethanol concentration in PS sample)

on the A526-glucose standard curve treated with potassium permanganate, $99.84 \mathrm{mg} \mathrm{L}-1$ of glucose would generate A526 of 0.4326 . By subtracting 0.4326 from 0.6850 , the A526 from total alcohols in the pretreated sample was calculated be 0.2524 . This A526 value was used to calculate the concentration of ethanol in the pretreated sample using the regression equation of ethanol standard curve, $y=6.94 x+0.0008$. The concentration of ethanol in the undiluted pretreated sample was $3.625 \mathrm{ml} \mathrm{L}-1$ after 100 -fold conversion.

\section{Application of the new method to monitor ethanol concentrations during the fermentation process}

We used the new method to monitor the increase in ethanol yield during the fermentation process by $Z$. mobilis in liquid medium ZM4-G30. Samples were taken daily from the culture. The concentrations of ethanol and remaining glucose were determined with the new method. The results was showed in Fig. 4. When the A600 of Z. Mobilis was increased as time went by until $160 \mathrm{~h}$. The concentration of ethanol reached the maximum level. The concentration of glucose went down until the last time we determined.

\section{Comparison between the new method and other methods}

The new method can be used in determination of ethanol not only in fermentation broths, but also in ethanol containing beverages including distilled spirit, beers and wines. We chose six commercial ethanol-containing beverages and a fermentation broth to determined their ethanol concentration using the new method and other methods (Fig. 5). Ethanol concentration was also analyzed by gas chromatography (Shandong Ruihong, SP-6890, China), carrier gas: nitrogen, capillary column (SE-54, Agilent, USA), injection temperature $150{ }^{\circ} \mathrm{C}$, flame ionization detector temperature
$160{ }^{\circ} \mathrm{C}$; Zheda Zhida Data Processor) and acetone was used as an internal standard (modified from [19]). The ethanol concentrations of three brands of distilled spirit were all in agreement with the ethanol concentrations analyzed by GC. However, they are quite different between potassium dichromate oxidation method and our new method in beers, wines and fermentation broth. This result indicates that the new method can be used in the ethanol concentration determination of ethanol containing beverage and fermentation broth. The new method is more precise and reliable than potassium dichromate oxidation method.

\section{Discussion}

The new method of determining alcohol and reducing sugars has several advantages over other methods currently used in the industry. First, it requires less volume of sample for detection. Using the new method, pretreated fermentation broth samples are usually diluted 10-20 folds, therefore only $100 \mu \mathrm{l}$ raw fermentation broth samples were needed. On the other hand, in gravimetric methods (GB/T 5009.48-2003), the volumes of sample to be distilled are usually at least $100 \mathrm{ml}$. If the ethanol concentration in the raw fermentation broth is $10 \%$, it requires about $1000 \mathrm{ml}$ of fermentation broth. If the concentration of ethanol is under $1 \%$, more than $10 \mathrm{~L}$ fermentation broth is required. Second, our new method is more accuracy and environment friendly than the potassium dichromate oxidation method. The potassium dichromate oxidation method $[11,12]$ is based on colorimetric changes upon chemical reactions with ethanol. This method cannot be directly used in determination of ethanol concentration in raw fermentation broths because of the presence of reducing sugars that can also react with potassium dichromate. With our new method, the noise caused by the reducing sugars in fermentation broths is effectively measured and subtracted from the total signal, allowing accurate determination of ethanol in the sample. However, potassium permanganate can react with non-reducing sugar, which cannot be detected by DNS. Therefore, this method can only be applied in the ethanol fermentation in which reducing sugars or polysaccharides of reducing sugars was used as carbon source. Our new method is more accurate than potassium dichromate method because the results of this method is not interfered by the presence of TCA, CTAB and other materials. In the new method, we used potassium permanganate as a replacement of potassium dichromate in the chemical reaction with ethanol and reducing sugars, thus avoiding the problem of carcinogenicity of $\mathrm{Cr}$ (VI). Therefore, the new method is more environment friendly.

Third, the new method is simply, fast, of low cost, and can be used in a high throughput manner. In this aspect, the new method has clear advantages over various gasand liquid-chromatographic methods, which, although 


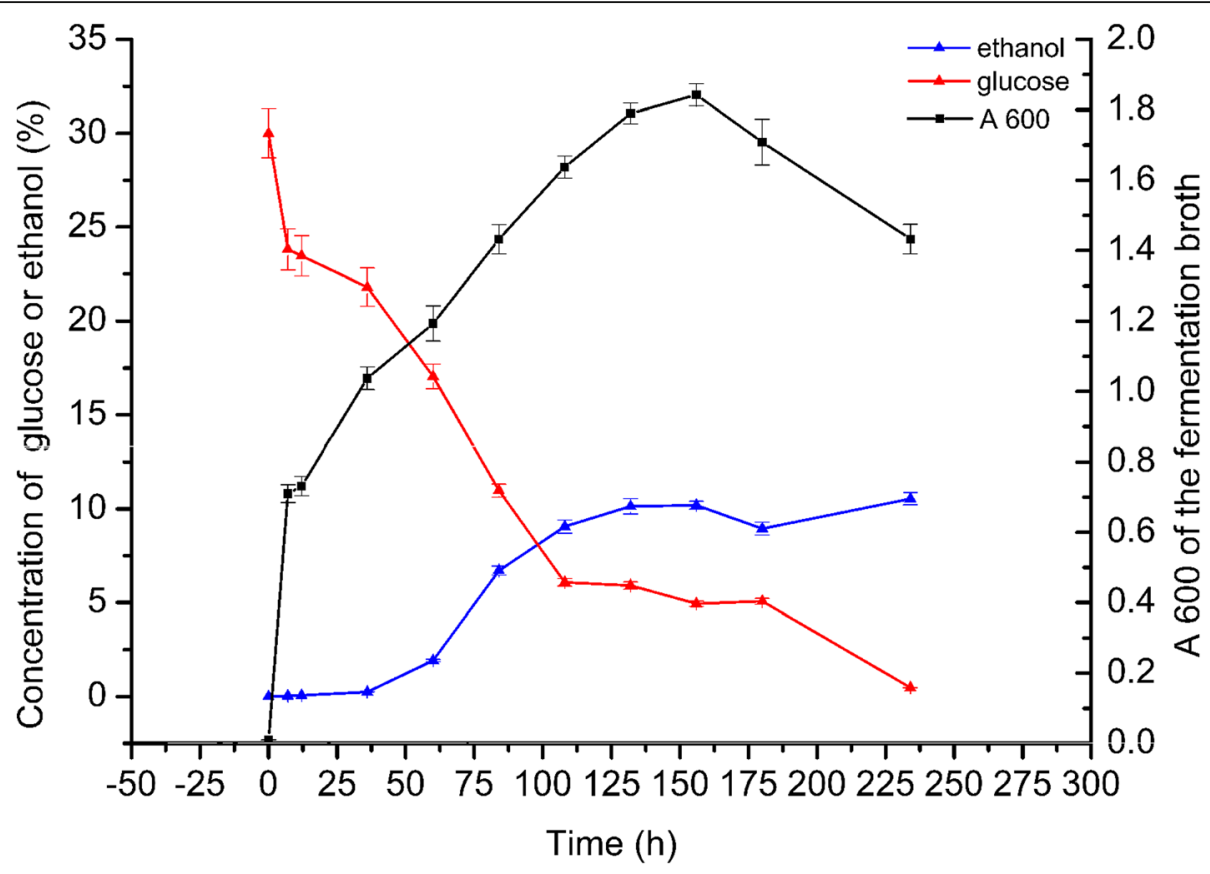

Fig. 4 The application of our new method to monitor the concentrations of total alcohols and remaining reducing sugars during a fermentation process

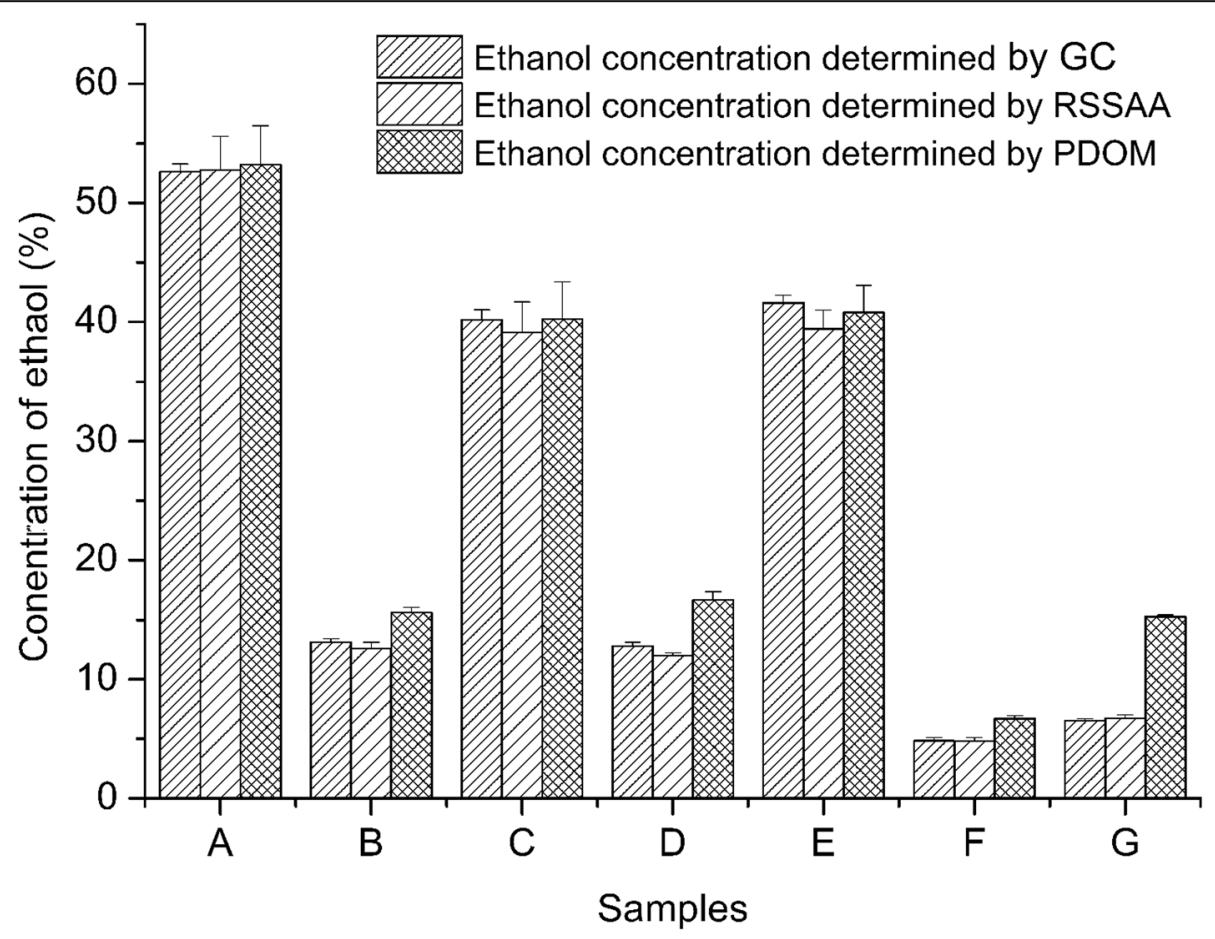

Fig. 5 Comparison of the new method and other methods. Maotai wine from China, b Jacob's Creek from Australia, c Absolut Vodka from Sweden, $\mathbf{d}$ Taster red wine from Chile, e Macaulay Whisky from Scotland, $\mathbf{f}$ Qingdao beer from China, $\mathbf{g}$ fermentation broth) 
pretty accurate, are usually complicated, slow, of high cost, and cannot be used in high throughput tests.

Fourth, in monitoring the process of ethanol fermentation, the concentrations of ethanol and reducing sugars are two important parameters. With the new method, not only the concentration of ethanol, but also that of reducing sugars, can be simultaneously determined. These results provide information in optimizing and regulating the fermentation processes.

There are some disadvantages in our new method. Potassium permanganate is not stable. It can react with water at low $\mathrm{pH}$ and complicate the test results. To minimize this disadvantage, the potassium permanganate solution should be prepared right before it is used and kept in dark. The standard curves of ethanol and glucose from the potassium permanganate treatment should be simultaneously established with the experiment samples.

\section{Conclusions}

A new analytic method was established to determine total alcohol concentration in fermentation broths. There are many advantages in this method: No precision testing instrument is needed. The results are reliable and precise. The operation process is easy and simple. Less volume of samples and reagents is required. The method is more environmental friendly. Multiple samples can be easily processed at a time.

\section{Methods}

\section{Medium and reagents}

ZM4 medium was prepared by dissolving $20 \mathrm{~g}$ of glucose, $10 \mathrm{~g}$ of yeast extract and $2 \mathrm{~g}$ of monobasic potassium phosphate in water to $1000 \mathrm{ml}$ and the $\mathrm{pH}$ was adjusted to 6.0. ZM4-G30 fermentation medium was made by adding glucose into the ZM4 medium to a final concentration of $30 \%$. All the media were sterilized by autoclaving at $121{ }^{\circ} \mathrm{C}$ for $30 \mathrm{~min}$.

DNS solution contains $6.3 \mathrm{~g}$ DNS, $262 \mathrm{~mL} \mathrm{NaOH}$ solution (2 M), $185 \mathrm{~g}$ Potassium sodium tartrate, $5 \mathrm{~g}$ crystallization of phenol, $5 \mathrm{~g}$ sodium sulfite in $1000 \mathrm{~mL}$. DNS solution should be kept in dark for a week at least before use.

Potassium permanganate solution contains $0.395 \mathrm{~g}$ potassium permanganate, $10 \mathrm{~g}$ Sodium tetraborate and 250 $\mathrm{mL}$ sulfuric acid (98\%).

Absolute ethanol, TCA, CTAB and glucose were all purchased from Sinopharm in China.

\section{Strain}

Zymomonas mobilis strain ZM4 (ATCC31821), which has been widely used in ethanol fermentation studies, was purchased from American Type Culture Center (ATCC).

\section{Sample preparation and pretreatment}

Ethanol fermentation by $Z$. mobilis was carried out in ZM4-G30 fermentation medium [3]. The fermentation cultures were centrifuged at $13,800 \mathrm{~g}$ for $5 \mathrm{~min}$ at $4{ }^{\circ} \mathrm{C}$. The supernatants were mixed with isovolumetric $20 \%$ TCA and kept at room temperature for $5 \mathrm{~min}$. Then the mixtures were centrifuged at $13,800 \mathrm{~g}$ for $5 \mathrm{~min}$. The supernatant was filtered with a bacterial filter $(\phi 0.22 \mu \mathrm{m})$. The supernatants were mixed with $1 / 5 \mathrm{vol}-$ ume of $20 \% \mathrm{CTAB}$, kept at $65^{\circ} \mathrm{C}$ for $10 \mathrm{~min}$, then centrifuged at $13,800 \mathrm{~g}$ for $10 \mathrm{~min}$. The supernatants were thereafter called pretreated samples. Two aliquots of the pretreated sample were taken, one for ethanol determination and another for reducing sugar determination.

\section{DNS treatment}

One pretreated sample aliquot was treated with DNS under alkaline conditions to determine the concentration of reducing sugars. The pretreated sample was diluted 10 -fold with water. The diluent $(200 \mu \mathrm{L})$ was mixed with DNS $(600 \mu \mathrm{L})$ and kept at $100{ }^{\circ} \mathrm{C}$ for $10 \mathrm{~min}$. After cooling down to room temperature, $200 \mu \mathrm{L}$ of the mixture was transferred to a 96-well plate. Absorbance at $550 \mathrm{~nm}$ was determined.

\section{Potassium permanganate treatment}

Another pretreated sample aliquot was diluted 100-fold with water and $100 \mu \mathrm{L}$ of the diluted samples was added to a 96-well plate. Then $100 \mu \mathrm{L}$ of potassium permanganate solution was added, mixed and kept at $40^{\circ} \mathrm{C}$ for $90 \mathrm{~min}$. Absorbance at $526 \mathrm{~nm}$ was determined.

\section{Test of completion of the reaction}

To determine the completion of the colorimetric reactions and the stability of the product, glucose and ethanol at various concentrations were treated with potassium permanganate solution as described in 2.4 and A526 was determined every $3 \mathrm{~min}$ up to $120 \mathrm{~min}$.

\section{Result calculation}

The concentration of ethanol in fermentation broth was calculated in 5 steps. Step 1, the A526 generated from the addition of potassium permanganate in the pretreated sample was determined as described in method 2.4 above, and recorded as 'A'. Step 2, the concentration of reducing sugars in the pretreated sample was calculated using the A550 generated in the DNS method as described in method 2.3 above, based on the glucose-DNS standard curve. Step 3, the portion of A526 contributed by the reducing sugar in the sample was calculated according to the standard curve of potassium permanganate method for glucose and recorded as 'B'. Step 4, the portion of A526 contributed by ethanol in the sample was calculated by subtracting $B$ from A. Step 5, the concentration of ethanol in the sample was calculated based on the standard curve of potassium permanganate reaction for ethanol. 


\section{Abbreviations}

CTAB: hexadecyltrimethylammoniumbromide; DNS: 3, 5-dinitrosalicylic acid; TCA: trichloroacetic acid

\section{Acknowledgements}

All authors are grateful for the guidance of HPLC method from Professor Baixiang Du in school of Chemistry and Material Science, Jiangsu Normal University.

\section{Funding}

The financial support of this research was provided by the Priority Academic Program Development (PAPD) of Jiangsu Higher Education Institutions, the Aid project for PhD faculties in Jiangsu Normal University (13XLR007), the National Nature Science Foundation of China (Project number 31300067), the Xuzhou Science and Technology Planning Project (KC14N0068), the National Natural Science Foundation of China $(31671944,31301585)$ and the Qing Lan Project of Jiangsu Province.

\section{Availability of data and materials}

The data collected upon which this article is based upon are all included in this manuscript and the Additional files associated with it.

\section{Authors' contributions}

Peng Zhang design the test methods and wrote the manuscript. Hao Hai cultured bacteria and prepared samples. Dongxu Sun revised the manuscript. Weihua Yuan potassium dichromate test of ethanol. Weijie Liu established the standard curve of ethanol. Ruru Ding established the standard curve of reducing sugar. Mengting Teng pre-treated the fermentation broth. Lin Ma calculated the data. Jun Tian tested the product stability of reactions. Caifa Chen tested the ethanol concentration using GC method. All authors have read and approved the manuscript.

\section{Ethics approval and consent to participate}

Not applicable.

\section{Consent for publication}

Not applicable.

\section{Competing interests}

The authors declare that they have no competing interests.

\section{Publisher's Note}

Springer Nature remains neutral with regard to jurisdictional claims in published maps and institutional affiliations.

Received: 25 October 2018 Accepted: 13 May 2019

Published online: 22 May 2019

\section{References}

1. Dasari S, Kolling R. Cytosolic localization of acetohydroxyacid synthase Ilv2 and its impact on diacetyl formation during beer fermentation. Appl Environ Microbiol. 2011;77(3):727-31.

2. Morales P, Rojas V, Quiros M, Gonzalez R. The impact of oxygen on the final alcohol content of wine fermented by a mixed starter culture. Appl Microbiol Biotechnol. 2015;99(9):3993-4003.

3. Zhang P, Chen C, Shen Y, Ding T, Ma D, Hua Z, Sun D. Starch saccharification and fermentation of uncooked sweet potato roots for fuel ethanol production. Bioresour Technol. 2013;128:835-8.

4. Garcia-Martinez T, Bellincontro A, de Lerma Mde L, Peinado RA, Mauricio JC, Mencarelli F, Moreno JJ. Discrimination of sweet wines partially fermented by two osmo-ethanol-tolerant yeasts by gas chromatographic analysis and electronic nose. Food Chem. 2011;127(3):1391-6.

5. Li H, Chai XS, Deng Y, Zhan H, Fu S. Rapid determination of ethanol in fermentation liquor by full evaporation headspace gas chromatography. J Chromatogr A. 2009;1216(1):169-72.

6. Zhang CY, Lin NB, Chai XS, Zhong L, Barnes DG. A rapid method for simultaneously determining ethanol and methanol content in wines by full evaporation headspace gas chromatography. Food Chem. 2015;183:169-72.

7. Nascimento ES, Cardoso DR, Franco DW. Quantitative ester analysis in cachaca and distilled spirits by gas chromatography-mass spectrometry (GC-MS). J Agric Food Chem. 2008;56(14):5488-93.
8. Neves LA, Rodrigues JM, Daroda RJ, Silva PR, Ferreira AA, Aranda DA, Eberlin $M N$, Fasciotti $M$. The influence of different referencing methods on the accuracy of delta(13) $C$ value measurement of ethanol fuel by gas chromatography/combustion/isotope ratio mass spectrometry. Rapid Commun Mass Spectrom. 2015;29(21):1938-46.

9. Cabanero Al, Recio $\mathrm{JL}$, Ruperez M. Simultaneous stable carbon isotopic analysis of wine glycerol and ethanol by liquid chromatography coupled to isotope ratio mass spectrometry. J Agric Food Chem. 2010;58(2):722-8.

10. Li X, Jia G, Cao Y, Zhang J, Wang L, Sun H. Simultaneous determination of delta13C values of glycerol and ethanol in wine by liquid chromatography coupled with isotope ratio mass spectrometry. Se Pu. 2013;31(12):1201-5.

11. Noriega-Medrano L, Vega-Estrada J, Ortega-Lopez J, Ruiz-Medrano R, Cristiani-Urbina E, Montes-Horcasitas Mdel C. Alternative nonchromatographic method for alcohols determination in Clostridium acetobutylicum fermentations. J Microbiol Methods. 2016;126:48-53.

12. Gros N. Microdiffusion-based UV-LED spectrometric setup for determining low levels of ethanol in fruit juice. Talanta. 87:174-9.

13. Guoqing H. Dictionnary of chemistry and chemical technology (in Chinese. Beijing: Chemical Industry Press; 2003. p. 751.

14. Grimbleby FH, Ntailianas HA. Binding of trichloroacetic acid by protein. Nature. 1961;189:835-6.

15. Rajalingam D, Loftis C, Xu JJ, Kumar TK. Trichloroacetic acid-induced protein precipitation involves the reversible association of a stable partially structured intermediate. Protein Sci. 2009;18(5):980-93.

16. Sivaraman T, Kumar TK, Jayaraman G, Yu C. The mechanism of 2,2,2 trichloroacetic acid-induced protein precipitation. J Protein Chem. 1997; 16(4):291-7.

17. Clarke JD. Cetyltrimethyl ammonium bromide (CTAB) DNA miniprep for plant DNA isolation. Cold Spring Harb Protoc. 2009;2009(3):pdb prot5177.

18. Teixeira RS, da Silva AS, Ferreira-Leitao VS, da Silva Bon EP. Amino acids interference on the quantification of reducing sugars by the 3,5dinitrosalicylic acid assay mislead carbohydrase activity measurements. Carbohydr Res. 2012;363:33-37.18.

19. Laopaiboon L, Nuanpeng S, Srinophakun P, Klanrit P, Laopaiboon P. Ethanol production from sweet sorghum juice using very high gravity technology: effects of carbon and nitrogen supplementations. Bioresour Technol. 2009; 100(18):4176-82.

\section{Ready to submit your research? Choose BMC and benefit from:}

- fast, convenient online submission

- thorough peer review by experienced researchers in your field

- rapid publication on acceptance

- support for research data, including large and complex data types

- gold Open Access which fosters wider collaboration and increased citations

- maximum visibility for your research: over 100M website views per year

At BMC, research is always in progress.

Learn more biomedcentral.com/submissions 